\title{
AO PÉ DA PALAVRA, CÉU ACIMA: entre-lugar de uma docência-menos
}

\author{
Cristiano Bedin da Costa \\ Universidade Federal do Rio Grande do Sul - UFRGS, Brasil \\ Marcos da Rocha Oliveira \\ Universidade Federal do Paraná - UFPR, Brasil
}

\begin{abstract}
Resumo
O texto discute o currículo a partir de seu deslocamento e de sua transformação na cena dramática da aula. Por meio da imagem de uma razão antropofágica, a experiência de formação docente é vinculada a procedimentos de autoatualização via assimilação crítica da alteridade por intermédio da palavra. A escrita toma como matéria tanto a revisão bibliográfica quanto a prática concreta de ensino no contexto das licenciaturas de duas universidades federais brasileiras, transversalizandoas. As discussões orientam-se por uma poética do menos, a qual é entendida como artifício de criação em meio a dispositivos macropolíticos de regulação curricular e subjetiva. Por fim, faz-se a defesa da aula como entre-lugar de um canto ex-cêntrico de apropriação e transcriação: ensino e aprendizagem amalgamados a um princípio de desejo, resistência e tradição de ruptura.
\end{abstract}

Palavras-chave: Currículo; Formação docente; Entre-lugar; Razão antropofágica.

\begin{abstract}
The text discusses the curriculum from its displacement and its transformation in the dramatic class environment. Through the image of anthropophagic reasoning, the experience of teacher education is linked to self-actualization procedures via critical thinking of otherness through the word. Writing transversely takes as its subject both the literature review and the concrete teaching practice in the context of teaching degrees from two Brazilian federal universities. The discussions are guided by minus poetry, understood as an artifice of creation amid macropolitical agencies of curricular and subjective regulation. Finally, the class is defended as a space in-between an ex-centric chant of appropriation and transcreation: teaching and learning amalgamated with a principle of desire, resistance and tradition of rupture.
\end{abstract}

Keywords: Curriculum; Teacher Education; Space in-between; Anthropophagic reasoning. 


\title{
Trabalho, os gestos da ideia
}

No curso de sua jornada, os argonautas substituíram gradualmente cada peça de sua embarcação. A imagem do navio que se renova por completo sem mudar o nome e a forma (que atravessam o tempo alheios às transformações do percurso), é retomada por Roland Barthes (2003a, p. 129-130) em sua autobiografia, como metáfora do trabalho com a linguagem por ele realizado enquanto professor e escritor. Esse trabalho, denominado trabalho da palavra, "consiste em dar a uma mesma frase inflexões sempre novas, criando assim uma língua inédita, em que a forma do signo se repete, mas nunca seu significado". Sem dúvida, perspectivar escrita e docência a partir de um esforço que, sendo conduzido dia a dia através do tempo, o faz certificando um modo de existência tão instável quanto reconhecível, faz com que tenhamos de admitir em nós mesmos a persistência de perdas e substituições de pedaços como um traço identitário fundamental. Em linhas gerais, isso implica defender aula e texto como ocasiões nas quais se evidencia - à força do estilo e da maquinação didática - o movimento insistente daquilo que, mesmo atravessando a ordem das coisas sensíveis e compartilháveis, não cessa de não se inscrever em sua transmissão. Acha-se primeiro o gesto, expressão do corpo, e ajusta-se o intertexto - os gestos da ideia, dirá Barthes. Quando uma prática, por sua própria força, é assumida como um esforço parcialmente realizado nas costas do exprimível, nada mais resta àqueles e àquelas que dela se ocupam além de afirmar a palavra em seu verso e reverso, tomando-a pelo avesso, conduzindo-a para longe de sua origem. Esta afirmação é em suma o tema deste ensaio.

\section{Semeadura menos: palavra, currículo e docência sem fronteiras}

\author{
Americana Pátria, morena \\ Quiero tener \\ Guitarra y canto libre \\ En tu amanecer \\ No pampa, meu pala a voar \\ Esteira de vento e luar \\ Vento e luar \\ Vitor Ramil, Semeadura
}

A escrita e a docência são nosso povo e nossa terra, nosso modo de rasgar o ventre da noite e beijar os relâmpagos em meio à escuridão do presente. Como gesto inicial deste ensaio, emerge a defesa de um comunismo das formas (Bourriaud, 2009), pelo qual apropriamo-nos e transcriamos notas contra-hegemônicas de diversas poéticas da diferença sob a marca do menos. Assim, desejamos prosseguir e semear manhãs e frutos e sonhos em meio a latifúndios macropolíticos de regulação curricular e subjetiva, subvertendo 
dispositivos de demarcação de limites para a expressão da vida, minorando cercas para estabelecer uma zona comum de exercício da alteridade crítica. Tratar-se-ia, então, de uma docência-pesquisa sem fronteiras.

Alçar o olhar, delinear o horizonte dos possíveis viáveis do presente, para então questionar se tudo aquilo que pensamos, dizemos, praticamos e sentimos em docência e pesquisa é, de fato, tudo aquilo que podemos pensar, dizer, sentir e praticar (Corazza, 2013). Em nosso campo, o mapa é imagem ativa e a palavra, pensamento em gestação. Viver a escrita e a docência em favor de um tempo, de uma terra, de uma educação e de um povo por vir. É em coincidência com o espírito de uma razão antropofágica (Campos, 2017), assumida como princípio de assimilação crítica e transcriadora de discursos ${ }^{1}$ em circulação no contemporâneo, que o texto, munido de seus intercessores, perspectiva a docência em formação desde uma lógica alternativa ao roteiro preferencial do currículo normativo.

Para tanto, tomamos um ensinamento que nos é legado por Barthes (2005) em sua última aula (a ocasião da última palavra, mas não a palavra final): lá aprendemos que o ato de criação tem início com o retorno a certo passado eleito, pelo testemunho de certos esforços já realizados, pela escolha ativa de uma filiação que se faz deslizar através de palavras novas e por gestos outros, com os quais se vive o desafio criativo do presente. Uma imagem de pesquisa então se enlaça à docência por meio da seleção, do deslocamento e da atualização de ideias com as quais definimos um estilo de presença nas lutas que nos cabe lutar: mastigando a herança cultural, nutrimos o impulso de renovação que inscreve o sumo diferencial de nós mesmos.

Um esgotamento voluntário, talvez. Deixar-se ir, agir por meio de retiradas e minorações, aceitar o chamado de uma aventura (Barthes, 2003a) - e não aderir ao esgotamento involuntário, imposto desde o exterior per via di porre (Freud, 2017). Desde já, isso deve querer dizer: afirmação de uma docência-menos, tal como a menoridade nos é legada por Haroldo de Campos (2017, p. 221-230) em "Arte pobre, tempo de pobreza, poesia menos". Extraído do ambiente dos usos criativos da palavra na literatura brasileira, o "procedimento menos" surge como o motor de uma política do texto na qual se lê o menos contra o mais. No ensaio de 1981, o que está em causa é a defesa de uma forma minoritária de engajamento na disputa pelas possibilidades de configuração da sensibilidade em um contexto regido pelo imperativo da opulência vocabular e normativa dos modos de comportamento e expressão. Pela verificação de uma linha rastreável de evolução poética nacional, a análise haroldiana se debruça sobre autores cuja qualidade diferencial está atrelada ao engenho de uma "magreza estilística", na qual a "baixa temperatura vocabular" trabalha em favor de uma "alta temperatura informacional estética". Assim, nomes como Machado de Assis, Oswald de Andrade, Drummond e Graciliano Ramos, entre outros, são reunidos por um mínimo múltiplo comum, que se traduz em uma solidariedade textual marcada pelo uso constante de um sinal de menos diante de dispositivos mecânicos e métricas quantitativas de escrita.

O mais contra o menos: algo assim não nos parece plenamente distante da dinâmica que aqui descrevemos como contemporânea, e as lacunas constituintes de uma poética subtrativa são isomórficas - em desejo - àquelas que buscamos em nossa docência-pesquisa. Através 
dela, o efeito dos espaçamentos dentro dos quais operamos o menos contra o mais define um estilo preciso de pobreza no interior da abundância que nos cerca: hiperinformação, hipercomunicação, hiperprodução de memórias digitais, rostos e existências transparentes, pornograficamente expostas, psicopolítica de elevação desmedida da temperatura da linguagem informacional e educativa (Han, 2017). Diante de tão farta oferta de modos de ser, sentir e agir, em que se poderia reconhecer uma docência que operasse per via di levare, subtraindo excessos regulatórios, diante dos quais prefere dizer não?

Suspenderemos o gesto nessa abertura, para retomarmos a operação ao longo do texto. Por ora, cabe-nos circundar o bloco e sermos educados pela pedra, escutarmos sua "voz inenfática, impessoal", visto que é por uma dicção concreta, lacuna da posse da palavra, que "ela começa as aulas" - como lemos João Cabral de Melo Neto (2008, p.207) - para, só então, afirmarmos a contundência, a lâmina da voz na palavra a palo seco.

Então, o mais contra o menos: alonguemos a disputa.

No quadrante educacional, em consonância ao espírito consumista da época, "grande parte das ações pedagógicas está fadada a uma vida curtíssima e, consequentemente, a um empobrecimento intelectual sem precedentes" (Aquino, 2014, p. 114). Enredadas em uma avalanche de ações marcadas por uma ânsia utilitarista, docência e discência carecem "de tempo para a lenta decantação de algumas poucas ideias, relevantes e sóbrias; relevantes porque sóbrias, sóbrias porque poucas". Em um tempo de elogios cegos a técnicas de controle e aprendizagem, diante de sistemas complexos de individualização e patologização do fracasso escolar, quando a experiência da sala de aula não deixa de reproduzir opressões vividas em outros contextos, o fantasma do não professor (Dunker, 2020), encarnado pela figura de um mero gestor de processos educativos, irrompe no horizonte de nossos processos formativos. Apartado de seu desejo, e por isso não sendo capaz de relacionar desejo e saber, o não professor nada pode fazer a não ser sustentar discursos sobre a educação, movimentando-se segundo as leis de um discurso e de um fazer nada educativos.

O grande combate hoje em curso [...] se dá entre os que estão interessados na circulação do saber e os que estão voltados para leis, normas e regulamentos pedagógicos. Há uma inversão simples entre meios e fins: a educação baseia-se em métricas, resultados e parâmetros. Ela rapidamente produz escolas que selecionam ou segregam alunos para o ENEM, tendo em vista a criação de aparências de resultados para atrair consumidores. Essa corrupção dentro da lei é o que se ensina ao final do processo; e, como tal, é o mesmo princípio que nos leva ao ensino apostilado, às matérias pré-fabricadas, aos professores recicláveis, aos cursos e faculdades para Inglês ver (Dunker, 2020, p. 199-200).

Por meio de uma operacionalização meramente metodológica, pela qual torna-se possível comparar práticas e medir resultados, orientar ações pedagógicas e definir macropolíticas públicas, o ato de ensinar cede cada vez mais espaço à ubiquidade quaseeducativa performada pelo não professor. Em sua presença, a transferência do desejo de saber transforma-se em simples identificação a jargões pedagógicos e a incontáveis prescrições de conduta relativas à fé cega na técnica educativa. 
Diante de tal cenário, é no entre-lugar de nossa pesquisa, de nossa docência e de nossa escrita que buscamos encontrar os modos de alastrar a palavra partícipe de uma tradição de ruptura do espaço-tempo. Da fé cega à faca amolada. Desde aí, semeamos o menos como princípio inventivo de nossas práticas, onde as matérias implicadas tematizam os fazeres e saberes curriculares enquanto "referentes para o seu campo de tensão polêmica" (Campos, 2017, p. 230). A palavra, se a tomamos, é para fazê-la trabalhar - o que implica, por extensão, prosseguirmos com o passo. Renunciando à disputa do absoluto, uma docência-menos permanece no campo magnético do desejo. Nele, diante de tantos dispositivos de controle engendrados por discursos reguladores do currículo e das práticas de ensino, "falar, escrever, significa: falar contra, escrever contra" (Santiago, 2019, p. 18).

O que está em causa é uma agressividade desviante e subtrativa, pautada por táticas de descontinuidade no fluxo consensual e rotinizado das ideias e dos discursos no campo educacional - táticas afins ao que Michel Foucault (2008) denominou tarefas negativas, dedicadas à ruptura com o jogo proposto por noções ligadas ao postulado da continuidade acrítica, jogo esse regido por ideais estáveis de identidade profissional. Uma vez que a visada minoritária aqui assumida diz respeito tanto a maquinações didáticas quanto a operações textuais implicadas em uma vida docente, é a própria palavra docente, considerada a partir das múltiplas variações de seu significado, que está em causa como matéria significante. Diante do risco de invisibilidade inerente à coincidência da cópia idealizada ao modelo imposto - lógica perversa cujos efeitos nocivos justificam a urgência e a relevância dos esforços intelectuais reunidos nesta Seção Temática -, interessa-nos a visibilidade própria das cópias imperfeitas, o desvio constituinte dos simulacros que exibem em cada ato a marca da diferença.

Eis então, em linhas gerais, o norte argumentativo deste ensaio: a proposição de uma docência caracterizada por subtrações relativas a dispositivos de regulação em marcha no contemporâneo, apontando para o potencial inventivo e para o traço de inatualidade constituintes do trabalho da aula e do texto tomados ao pé da palavra, com seu desequilíbrio e sua tensão significante - o que ao mesmo tempo quer dizer: uma docência forjada em uma zona de distância crítica da adesão plena, da reprodução fiel e da sedução do sentido entoado por uma fábula formativa.

Para tanto, o que virá a seguir está organizado da seguinte maneira: em um primeiro momento, traçamos um pequeno mapa de leituras com as quais é demarcada a especificidade de nosso tempo. Em sua maioria, textos recentes, escritos sob o signo pandêmico e publicados no Brasil por diferentes meios. Ao filtrar parte desse conteúdo existente - o arquivo de nossa memória coletiva - entendemos ser possível, por meio de ablações, aproximações, choques, trabalhá-lo de modo a atualizar algumas chaves interpretativas do contexto contemporâneo. Trata-se de um mapeamento de assimilação crítica, de aprendizagem e reação desprovida de obediência. Em seguida, apresentamos o trabalho com a palavra como ferramenta de análise para pensar a questão da formação docente, em especial a partir da ideia de uma formação desejante. A especificidade da ação didática é definida pelo modo como nela são articuladas fala e silêncio, sentido e não sentido, o transmissível e o não transmissível em um contexto de trabalho com signos da cultura na construção de uma comunidade pedagógica. Nesse 
meio, a palavra surge como condição de possibilidade de um entre-lugar relacional em sala de aula, sendo a noção de entre-lugar, na esteira do pensamento antropofágico de Silviano Santiago (2019), entendida como uma zona de descondicionamento subjetivo e minoração de práticas curriculares hegemônicas. Por fim, assumimos um contracanto como operação de uso da palavra, cinzelando a imagem de uma docência-menos de encontro ao bloco macropolítico de regulação curricular e subjetiva.

\section{Céu acima, no entre-lugar dos currículos}

A interdependência universal de nações, prenunciada por Marx e Engels em 1848, é atualizada para o contexto cultural brasileiro por Haroldo de Campos (2006), sob a marca de uma devoração planetária - "Marxillar", assinará Oswald de Andrade (2017, p. 63-64) o seu Porque como, texto que defende a necessidade de uma "descida antropofágica" diante da realidade social verticalizada por padrões colonizadores (a altura política do mapa-múndi como planisfério está reservada àquelas palavras ao norte, ao céu dos conceitos que se pensam imperativos). Por diferentes formas, constata-se que a antologia das formas de produção do espírito preserva alguma distância das formas de produção material - assim o diz o manifesto aludido ou como preferimos escrevê-lo: céu acima ao pé da palavra. Claro está que o sociologismo ingênuo poderia aqui abater-nos, caso a vida ao sul aceitasse as interpelações político-econômicas de uma narrativa rota sobre desenvolvimento e subdesenvolvimento - refugos da ideia de progresso econômico e social, como bem o diz Octavio Paz (s/d). O arco e a lira de Paz estão no oco de nossa guitarra e na tensão de nossas mãos.

Mas, "se diz a palo seco/ o cante sem guitarra;/ o cante sem; o cante;/ o cante sem mais nada" (Neto, 2008, p.67): sabemos que as noções não pairam no mundo das ideias, mas são colhidas pela mesma mão que semeia. A palavra que nos cabe participa de tal diálogo com o universal, com os temas geradores de uma época, com a imagem do firmamento em descida via transculturação: voragem que se apropria de certo passado de criação que julga necessário e que ao fazê-lo expropria os signos da submissão via uma alteridade modal. O labor da palavra é uma mordida na mão que alimenta.

Os modos de atualização da palavra vital exprimem a um só tempo uma genealogia crítica e uma pedagogia exploratória criativa. Descida dedilhada, gesto que faz vibrar. Ao dizermos de uma contemporaneidade, selecionamos as estratégias de resistência a serem operadas no arquivo. Preparamos, de tal modo, o corpo estrangeiro com o sal e o vento da terra - nossos possíveis viáveis que se mostrarão em seguida. E é assim que contamos aos demais corpos viventes o tempo presente que nos cabe viver - o que é o mesmo que dizer: espaço onde resistimos, construímos e desejamos.

Contemos, pois.

O agravo estridente da complexidade contemporânea se expressa em uma pandemia desprovida do prenúncio de seu fim, saturando os dias com expressões da desigualdade e da exploração da vida. Judith Butler, em Traços humanos nas superfícies do mundo (2020), 
diagnostica o quanto tal acontecimento mundial nos mostra concretamente a interconexão entre os habitantes da Terra, ao passo que essa interdependência (já para muito além da ideia de nações) não se perfaz no regozijo comunitário global, mas antes na imersão em relações pautadas pela extenuação das forças vitais alheias e pelas mais variadas formas de desigualdade social.

Ampliando o espectro de uma comunidade vital global, Juliana Fausto, em Contra quem se vingam os animais? (2020), irá mostrar a necessidade imprescindível de uma política polifônica, multiespecífica, de modo que a morte em vida que a humanidade produz atualmente - por intermédio de um ensimesmamento, transformando tudo em si mesmo cesse. Nesse mesmo diapasão, Achille Mbembe afirma $O$ direito universal à respiração (2020) em meio ao brutalismo de nossos tempos, estruturalmente composto pela toxicidade, pela exposição constante a riscos biológicos e pela produção incessante do esgotamento físico dos múltiplos corpos vivos.

As assimetrias potencializadas e evidenciadas pelo neoliberalismo e a aceleração de suas estratégias paradoxais de gerenciamento da vida e da morte se materializam em políticas virtualizadas concretas. Permanecendo com o problema, Donna Haraway (2020) afirmará a importância de semearmos mundos nos quais possamos subtrair as possibilidades de uma dupla morte - aquela que acontece ao corpo que vive e à possibilidade de continuidade da vida de certa comunidade (o cancelamento de certas formas de fazer circular a palavra). Assim, quem sabe, minorando essa dimensão suplementar e atual da morte, possamos viver e morrer como um florescimento contínuo em Gaia. Talvez por isso, a dimensão metalinguística que o vírus adquire com a atual pandemia extrapola qualquer narrativa puramente biológica. Mizoguchi e Passos (2020) sustentam o quanto há de redundância no presente, de modo que estamos diante de mais um sintoma de uma política mais e mais ampla e a ampliar-se desmesuradamente em modos de regulação e gerenciamento que perfazem nossos modos de existir em um estado suicidário, de acréscimo, aceleração e acúmulo de mortes. A resistência a tal situação, talvez, esteja na mudança de uma mutação forçada para a assunção comunitária de uma mutação deliberada, como propõe Paul B. Preciado (2020), subtraindo as formas de biovigilância planetária como uma forma de estruturação de uma cooperação global. Esgotar o ensimesmamento contra o ensimesmar o esgotamento. Outra vez: o menos contra o mais.

Dado tal cenário, não é sem medida ou de se espantar que as atuais formas de autoexploração psicopolítica (Han, 2018) redundem em comandos e demandas constrangedoras da docência, amolando as capacidades de viver e criando esgotamento e depressão via adição suplementar de camadas de ensimesmamento. Em escala curricular ampla, a comunidade planetária vive essa constante aceleração e aumento da temperatura, no âmbito de "um parlamento de corpos vivos (vulneráveis) que habitam o planeta Terra" (Preciado, 2020, on-line) - sem o devido (contra)canto e as notas de futuro de sua alteridade. $\mathrm{Na}$ atual plenitude da luz que assola a docência (telas digitais e produção ininterrupta de energia para o armazenamento e o gerenciamento de dados, oriunda da queima de combustíveis fósseis), parece residir uma tentativa de adição infinita, visando acabar com o vazio necessário para o luar e o amanhecer no campo pedagógico. $\mathrm{O}$ atual estado da educação 
e sua expressão em políticas curriculares que negam o direito de uso criativo das palavras e ao mesmo tempo obrigam outras a serem ditas, comporta interpelações à docência que participam de tais dinâmicas e dramatizam ao seu modo aquilo que narramos como característica global de um agora. A vigilância está a um print, a um traço recortado da aula, a uma pequena filmagem. A caça à palavra que ensina se prenuncia na militarização das palavras de ordem, na ausência de escuta, na violência de um meme ou na invasão de salas virtuais pela milícia do pensamento.

Sejamos diretos: estamos derrubando moirões durante a passagem de um "regime patriarco-colonial e extrativista, de uma sociedade antropocêntrica e de uma política onde uma parte muito pequena da comunidade humana planetária se autoriza a levar a cabo práticas de predação universal", quiçá para uma comunidade capaz de "redistribuir soberania e energia" (Preciado, 2020, on-line), de compartilhar campo e mar, vento e luar, amanhecer e palavra.

Nós vamos prosseguir?

A passagem de regimes aludida, como vimos, constitui-se como desafio para quem vive o campo da docência escolar e universitária. Trata-se de um tempo de subtrações ativas como única possibilidade de viver diante da lógica da saturação informacional e da hiperprodução desejante - cabe-nos agir per via di levare. Amplamente, a luta se dá e se unifica em uma espécie de disposição para a desaceleração do consumo de toda a ordem, o que tende a um resfriamento potencial do sistema. É com um vagar ativo que a ação pedagógica espera e combate a obsolescência que aturde as aulas emergencialmente virtualizadas (Munhoz; Costa; Lulkin; 2000), promovendo exercícios de lentidão como componentes de processos de autoatulização (hooks, 2017) engajados no arrojo da resistência. Aparentemente, a crista do horizonte também estampa o menos contra o mais, e prosseguimos criando a cinzel as lacunas de sentido e os exercícios de vacância e largueza da palavra dita e escutada.

Claro está que a docência tem sido eivada por conclames a um protagonismo de desempenho criativo e paradoxalmente constringente, dada a centralidade pressuposta em sua capacidade de operar influências específicas. Talvez, por isso a ambiguidade que se perfaz no campo da educação, interpelada pelo embaraço de influenciadores e criadores de conteúdo disponíveis para o entretenimento total e por procedimentos que participem de tal lógica. Uma docência onde os dados são a alma do negócio e a alma do negócio são seus dados de desempenho. Rapidez e embaraço multimodais de telas e games: a parametrização curricular quantitativa que faz de uma vida de docência a explicitação de cinco ou seis somas a ilustrar o card de uma personagem. Joga-se tais cartas à transparência. Soma-se, ainda, a horda livre da polícia das ideias (tornada milícia virtual), que também entra no jogo à caça de palavras a serem silenciadas duplamente (como variação da dupla morte abordada por Haraway, não só o silenciamento mas a impossibilidade da continuidade da palavra). "Para gerar mais produtividade, o capitalismo da emoção também se apropria do jogo, [...] 'gamifica' o mundo do trabalho e da vida" (Han, 2018, p. 69) e interpela a docência no âmbito das recompensas imediatas e do engajamento emocional que gera mais desempenho e mais rendimento.

Somos a caça, que fique posto. 
Sob as luzes de mil telas portáteis, assistimos a aceleração da incidência de períodos avaliativos e o crescente número de dispositivos de avaliação em escala larga e global. Os modos de registro e parametrização da pesquisa e da docência estão em constante atualização, fazendo coexistir plataformas diversas e aumentando o medo diante da possibilidade de saturação do sistema e perda de dados. Perder os dados é correlato ao completo apagamento de si, ao aniquilamento de um longo tempo de vida. Enquanto preenchemos mais um formulário para o lançamento e atualização de dados, a seara da aula vê o sulco de suas palavras pisoteado, na tentativa de fazê-la um lote para a caça de profissionais que não estejam adequados ideologicamente à crença da quantificabilidade e mensurabilidade total da vida. Vemos o quanto o ataque à educação compõe um balido incomum, um apito de caça ao mesmo tempo anunciando o perigo da docência para com os modos presentes de viver (e com as imagens saudosas de um passado), bem como propalando sua ineficiência e obsolescência - ou seja, a educação como possibilidade criativa de semear sonhos e outros mundos possíveis, mas que ao mesmo tempo não se aguenta em pé diante do chamado ao mundo atual. Fé cega nas telas a cegar. Presenciamos a vigília docente em uma aula perigosa e em estado de vigilância.

Por outro turno, o descaso com a especificidade da ação docente ganha os mais atualizados traços de precarização do trabalho - cujo sinal dos tempos é a própria exploração sem limites de suas capacidades por meio dos vínculos pulverizados por aplicativos que anunciam a docência como prestação de serviço precarizada (chamada vulgarmente de "uberização"). Aliás, postos à prova dos mil, sentimos que o esgotamento é operado pela exposição reiterada às telas, pela transparência total que se presentifica na transformação da casa em cenário de aula, pela reprodução infindável das aulas virtualizadas transformadas em big data (Han, 2018), ou mesmo pela estimulação luminosa em tempo contínuo. Dessa forma, o insone não sonha, mas consome e produz em jornadas exaustivas. E então, o controle opera por instituições e mecanismos de avaliação que interpelam discentes a avaliarem a docência pela lógica de likes e por órgãos estatais calcados na métrica de engajamento gerados. Temos, enfim, a repetição atual da regulação da atuação docente, sem tréguas (o algoritmo de uma rede social que interpela e avalia uma publicação qualquer traveste-se de sensor a avaliar os resultados da sua pesquisa e da sua docência) - sem fim. A fórmula perfeita do ensimesmamento adiciona cada vez mais situações e experiências, tornando-as aptas a performar a submissão a seus termos.

Cá estamos, nessa passagem por vezes aterradora e por outras prenhe de um outro tempo. Mais e mais, mais e mais rápidos, mais e mais eficientes, mais e mais adequados aos parâmetros gerais, mais e mais engajados ao desempenho expresso por discentes ajustados ao campo dos resultados, das reiterações de si mesmo. Mas, não só. De toda sorte, semeamos aquilo que carece de certa lentidão e, por isso, é incapaz de ser gamificado. As qualidades de um trabalho longo e lento não são compatíveis com a temporalidade do game. "Caçar [...] corresponde de certa maneira ao jogo, enquanto as atividades de um agricultor, dependentes do amadurecimento lento e do crescimento silencioso, escapam à gamificação" (Han, 2018, p. 69). A tal tempo, de atenção total, indistinta e irrestrita a todo e qualquer dado, cena do controle e da caça às bruxas da docência, buscamos subtrair os pequenos imperativos de 
poder e as respostas e recusas comuns, como um modo de lembrar que a vida não se deixa transformar completamente em caça, e a docência se faz sarapintada de palavras: semeadura menos.

Cantemos, agora.

Acompanhados dos sons de nossa palavridade.

\section{Ao pé da palavra, docência-menos}

À maneira de um escultor que retira do bloco de pedra os excessos que escondem a superfície de uma forma singular - a forma potencial, em vir-a-ser -, tomamos agora, do currículo, aquilo que nele há de mais contingente: a palavra. É pela palavra, pelo modo como nela estão articulados o ensino e a aprendizagem, o dizer e o ouvir, o ver e o ser visto, o contar e o ser contado, que passamos a nos debruçar sobre a docência, sua formação e seus gestos performativos na cena dramática da aula. A palavra, significante maior, enquanto garantia de indução do desejo à sua exploração por diferentes bocados de saber (Barthes, 2003b), isto é, a palavra como grau zero da pesquisa, força motriz do planejamento, do texto, da aventura pedagógica.

Todo processo colonizador tem início pela proposição de uma língua como condição de entendimento. Por sua vez, a imposição do falar, em detrimento do tempo de escutar, constitui uma chave de leitura que permite compreender a atual pervasividade de discursos puramente administradores, estatísticos, tecnólogos e moralistas de ensino. Em seu exercício particular com a palavra, o professor não deixa de estar do lado da fala. "Falar para ocupar currículo, falar para disciplinar, falar para ensinar" (Dunker, 2020, p. 14). Desse modo, parece-nos que é pela apropriação da palavra, pelas incontáveis dimensões de seu uso, que são estabelecidos os limites e possibilidades do processo formativo.

Fundamento e princípio do poder da ação educativa, a palavra, seja sustentada pela presença, seja a própria presença feita palavra ou a palavra que oscila entre o diálogo e o silêncio, a palavra do mundo encarnada na aula, real "tabuleiro de guerra, canibalização: o inimigo sorvido, deglutido e expelido" (Aquino, 2019, p. 435), a palavra que aqui é matéria plástica, ponto desde onde o currículo é apropriado, deslocado pela fala transmutada em escrita, a palavra em sua dimensão de leitura ou escuta, a palavra lançada, errática, desapropriada, é por essa palavra, nela, em seus arredores, entre a assimilação e a expressão, entre o código e o desvio, entre a vontade de saber e a ignorância, a palavra exata, isto é, proteiforme, palavra entre-lugar, é nela que nos interessa pensar, dizer e viver a docência.

Sabe-se que há tempos o discurso universitário nos faz ouvir a crença de um saber mensurável que se deve transmitir integralmente. Delineia-se assim a imagem do mestre que retém e endereça as letras e as cifras com as quais se poderia ler o real, e sua tarefa estará realizada com perfeição se a operação de transmissão for feita a pleno, sem restos. Mas de que modo medir e avaliar a transmissão do saber? De que modo acreditar em uma unidade de medida precisa, crer em "uma espécie de cálice de graduação capaz de transferir 
integralmente um conteúdo de saber perceptível na passagem de um a outro continente" (Lollo, 2013, p. 15)?

A palavra como divisa.

Considerando que uma aula é regida por um princípio necessariamente relacional, de modo que o professor, ao endereçar-se ao outro por meio da palavra de seu saber, estabelece uma dinâmica entre dois sujeitos desejantes (ou seja, não-passivos), a matéria em causa em uma ocasião de ensino nunca é neutra. Ao desejar transmitir aquilo que sabe, o professor é aquele que traça uma superfície através da qual se pode ler um caso de perda e ganho, gesto duplo, que atenta tanto para o que é passível de ser apreendido quanto para o que necessariamente deverá ser produzido, in-formado, já que é algo que deriva do encontro. Seu ofício, assim, não se encerra na transmissão de conhecimentos e conteúdos que ele aprendeu e domina, envolvendo também "a relação que ele tem com o saber do qual também se torna autor ao tornar seu o que lhe foi legado" (Dunker, 2020, p. 199). Longe de constituir um caso de vocação, isso quer dizer empenho desejante naquilo que se faz. Pela presença de sua palavra, transmite-se uma competência, "monta-se um espetáculo (o de um fazer), em que o aprendiz, atravessando a ribalta, se introduz pouco a pouco" (Barthes, 2004, p. 418).

Interessa-nos tal divisa dramática, sob a qual temos agenciado nossa prática de docência e pesquisa no contexto das licenciaturas. Em Ensinando a transgredir, bell hooks sugere que pensemos o ensinar como um ato teatral. Não se trata de fazer do professor um ator e nem da aula um espetáculo. O que está em causa no aspecto teatral do ensino são as diferentes modulações do corpo e da voz que se quer engajada, os diferentes gestos que são sustentados e tons que são atingidos na construção de uma comunidade de aprendizagem. "Para lecionar em comunidades diversas, precisamos mudar não só nossos paradigmas, mas também o modo como pensamos, escrevemos e falamos" (hooks, 2017, p. 22). No limite, trata-se de entender não apenas a aula, mas também a palavra e a identidade docentes como obras abertas, em diálogo com o mundo que lhes é exterior. Assim como o escrever, o ensinar é "o modo de quem tem a palavra como isca" (Lispector, 1998, p. 21). A palavra pela voz que se projeta e busca o que não é palavra, a palavra que visa a entrelinha, o espaço vazio, o ainda não pensado. É nesse ponto de subdesenvolvimento que a criação é também autocriação; "ou seja, um diferenciar, diferenciando-se" (Corazza, 2018, p. 112).

Tal estética relacional permite delimitar certa especificidade poética de nossa prática enquanto professores. Uma especificidade criadora que é tanto ética quanto política, baseada em um esforço constante de reparação. Ora, se o estatuto mesmo da palavra "passou por transformações decisivas com a versão brasileira do neoliberalismo, com a disseminação da cultura digital e com as novas formas de individuação" (Dunker, 2020, p. 20), notadamente concernentes à coação expositiva e à volatização da experiência a ela inerente, parece-nos que é tarefa que nos cabe a devolução com fins restauradores da palavra tornada transparente e vazia àqueles e àquelas de quem foi arrestada - para que também seja possível o engajamento no ato de tomar a palavra para si, modulando-a em um exercício duplamente formativo: a palavra pela docência, a docência através da palavra. A docência, pelo trabalho de apropriação e circulação da palavra, torna-se também o gesto de sustentação de um horizonte temporal estendido e mais precisamente humano, sem dúvida. 
Pelo transcorrer dessa "temporalidade dos viventes" (Han, 2018, p. 93) em atuação em uma aula, a assistência à palavra é uma fração constituinte das obrigações compartilhadas por seus sujeitos. Ao mesmo tempo que é ponto de passagem e de articulação entre a escuta e a fala, a palavra carrega em si o conflito entre o ensino e a aprendizagem, o saber e o não saber. Eis o seu protagonismo. Diante dele, parece-nos que o fazer docente, seja por meio de quem o encarna de fato, seja pela perspectiva de quem em seu caminho está, reveste-se tanto de seu componente sonoro quanto de seu silêncio. Porque um professor é aquele que se debruça sobre a história do mundo, naquilo que nela há de currículo e de vida. É ele aquele que se coloca entre o passado e o futuro (Arendt, 1979), demarcando a posição de quem encarna um saber e uma voz anteriores, dados esses com o quais define a sua prática presente. Mas o professor é também aquele que, ao querer transmitir, faz com que a palavra deslize de seu sentido, torne-se insignificante ou outra coisa qualquer. Interessa-nos entender tais perdas como gestos estratégicos, artifícios criadores, operações de menoridade. De antemão, isso implica deixar de ver como deficiência certa fração de saber vinculada à perda relativa ao que é mensurável em uma relação educativa.

Desertemos a perda e o elogio de sua perspectiva, portanto.

Uma outra imagem, bosquejada em relação de proximidade com o léxico psicanalítico freudolacaniano, chega-nos outra vez através de Roland Barthes, na conhecida passagem com a qual apresenta o imaginário do ensino que então se iniciava no Colégio de França:

Gostaria pois que a fala e a escuta que aqui se trançarão fossem semelhantes às idas e vindas de uma criança que brinca em torno da mãe, dela se afasta e depois volta, para trazer-lhe uma pedrinha, um fiozinho de lã, desenhando assim ao redor de um centro calmo toda uma área de jogo, no interior do qual a pedrinha ou a lã importa finalmente menos do que o dom cheio de zelo que deles se faz (Barthes, 2007, p. 42).

No interior dessa pequena aventura privada, que se desenrola segundo o ritmo das idas e vindas do desejo de saber, descortina-se a cada aproximação e recuo a trama complexa de incitações que envolvem a poética de um aprendizado relacional. Trata-se de uma zona de encontro e passagem, um dinamismo espaço-temporal tão efêmero quanto irrepetível e nãoprogramável. Nessa zona, o que está em causa não é exatamente o conteúdo, e sim a sustentação de uma postura ${ }^{2}$ - o ethos que garante a distância segura, a entrada em cena de um saber materializado em gestos suspensos ao fio do desejo.

Em um plano mais íntimo, concernente à pesquisa, Barthes (1984, p. 36-39) lançará mão dessa lógica da atração em seu estudo sobre a fotografia, no qual a construção do corpus (o pequeno conjunto de imagens utilizadas no estudo) obedece ao que ele denomina "princípio da aventura", definido como a "animação" que lhe causavam certas fotos - animação essa que não é relativa ao referente, ou seja, a foto em si não precisa ser animada, o que ela deve sugerir é a abertura de um espaço exploratório: "eu queria aprofundá-la, não como uma questão (um tema), mas como uma ferida: vejo, sinto, portanto noto, olho e penso". 
Essa ideia de algo a mais que advém (seja da relação entre o sujeito e objeto, seja de uma relação intersubjetiva), produzindo uma animação, ajuda-nos a compor a imagem de um processo formativo perspectivado pelo assombro, pela surpresa, por sublevações de diversas ordens. "Ensinar (fazendo pesquisa) e pesquisar (ensinando) consistem, dessa maneira, em criar soluções e, ao mesmo tempo, enigmas" (Corazza, 2013, p. 94). Por uma palavra lançada; por uma frase proferida; por uma resposta retardada ou suprimida; por uma montagem de atrações em forma de plano; por roteiros imprevistos, pelos quais se instaura um traço de pensatividade: é quando a matéria sugere o sentido, sem encerrá-lo jamais. O princípio de aventura é regido por um desejo de saber cultivado em um campo exploratório aberto pelo encontro: como uma cegueira instaurada pela força do olhar.

Parece-nos que o princípio da aventura, com o estatuto de pensatividade que lhe é inerente, situa o trabalho da palavra docente como uma espécie de esforço arquitetônico, vinculado à instauração e preservação de entre-lugares.

Quando foi proposta por Silviano Santiago, em ensaio publicado em 1971, a noção de entre-lugar constituía uma ferramenta de análise da posição do discurso latino-americano perante o legado cultural imposto pelo colonialismo ocidental. Diante dos referenciais estrangeiros, as mãos e os gestos criadores agenciados nos trópicos instituíram "seu lugar no mapa da civilização ocidental graças ao movimento de desvio da norma, ativo e destruidor, que transfigura os elementos feitos e imutáveis que os europeus exportavam para o Novo Mundo" (Santiago, 2019, p. 19).

Retrabalhada por diferentes áreas de estudos pós-coloniais, a noção hoje aponta para diversas possibilidades de existência, no contemporâneo, de zonas periféricas ativas, marcadas pela relação de diálogo crítico entre suas partes. Para nós, interessa pensar essas fronteiras porosas e maleáveis, que traçam espaços de limites imprecisos, onde dentro e fora são constituintes de uma mesma condição. Mais precisamente, importa pensar nessas zonas híbridas enquanto fronteiras que se tornam "o lugar a partir do qual algo começa a se fazer presente" (Bhabha, 2001, p. 24). Pensar em termos de uma docência-menos é um ato que só pode se instaurar pela defesa da aula como ocasião onde o saber é também algo liminar, incerto, fundado a partir de uma aventura antropofágica diante da alteridade.

Faz-se necessário, então, defender a palavra docente articulada por um falar que ao expor, sugerir, fazer aparecer um mundo, o faz "de maneira que ele mantenha sempre algo de enigma, algo de intriga, que pode fascinar" (Masschelein, 2021, p. 36). É necessário isso e mais, ainda. $\mathrm{O}$ que nos parece decisivo, constituindo assim a real condição de possibilidade de um entre-lugar formativo, é que não apenas o estilo de presença do professor determine o direcionamento da palavra como uma via de mão única, mas também que a palavra em trânsito crie uma zona de contágio dentro da qual os limites entre o saber e o não saber tornam-se imprecisos - justamente porque a palavra de um novo saber, o saber derivado, comum, faz-se ouvir.

Daí que desdobrar a formação em um plano de consideração minoritário pode lembrar (mas de modo algum reproduzir termo a termo) o tom trágico - na medida em que é confrontado com uma tarefa inexequível - que constitui o que Renato Mezan denomina paradoxo do Bildungsroman psicanalítico, marcado por uma espécie de avanço hesitante, 
cujo progresso indica a ocupação de uma posição mais distante de seu perfazer-se. Diante da imagem de um acabamento definitivo, sem virtualidade de mudança ulterior, melhor seria "pensar em termos de aquisição de condições suficientes, como no caso do artista" (Mezan, 2005, p. 185). Porque, quando perspectivada por "uma certa relação produtiva com a ignorância, uma relação potente com o não-saber, ou com o não-ainda-sabido" (Dunker, 2019, p. 16) - na medida em que essa lacuna de sentido é uma espécie de propedêutica para a pesquisa - a aventura formativa coloca em causa um saber não instrumental, "como um saber para fazer", mas sim "um saber reflexivo sobre o próprio fazer" (idem, p. 270). O mapa, com a indicação do roteiro e as marcas de nossas pegadas deixadas no percurso, define tanto aquilo que somos quanto os limites para uma experiência de alteridade.

Desdobra-se assim uma noção de formação sem reconciliação final, o que não quer dizer que nela não existam etapas vencidas e momentos superados. O que está em questão é o modo de existência do sujeito diante do saber, de forma que seu exercício não dirija-o até a identificação com uma figura padrão, seja ela estabelecida por diretrizes curriculares ou pela maneira como o papel docente é encarnado em uma relação transferencial específica. Ao contrário: o processo de formação é antes o exercício incessante de formação do desejo docente, isto é, o estabelecimento das condições necessárias para se fazer a renúncia da necessidade de identificação, já que reside nessa mesma renúncia a possibilidade de alguma produção desejante. $\mathrm{O}$ desejo docente, que aqui defendemos em seu desdobrar-se, palavra por palavra, na vontade de aula e de texto, separa-se assim do desejo de conformidade a algum modelo proposto, uma vez que tal aproximação sempre irá colocar em causa critérios anteriores à experiência.

Forjada no campo de possíveis aberto pela aula e pelo texto, uma vida docente é operada ao pé da palavra, entre a leitura e a escrita, o falar e o escutar. Atravessada pela presença inalienável do outro, seja outro alguém ou outro modo de pensar, seus sentidos são determinados pela agonística “eu-n'outro/outr'em-mim" (Naffah-Neto, 1998, p. 71). Ars combinatoria, portanto, um modo de existência falquejado no indispensável movimento dialógico da diferença que marca a presença do outro. Não há autoatualização que não contenha certa dose de despedida de si, por meio de uma montagem relacional e inventiva.

As implicações de tal perspectiva para a formação docente funcionam como traços constituintes de uma docência eivada por um sinal de menos. É quando a transmissão está vinculada a um saber cuja recepção se confunde com a produção, quando a palavra docente carrega em si mesma a animação de um intransferível porque ainda não formalizado, é no ponto preciso em que a transmissão cede a palavra ao intransmissível, isto é, quando ela ecoa o silêncio do sentido que se reproduz em ato, quando deglutido e assimilado pelo outro em sua própria aventura formativa, é, em suma, quando a aprendizagem se confunde com a reprodução do que lá não estava - é ali, nesse lugar aparentemente vazio, terra móvel, entre a submissão ao código e sua transvaloração, ali é que se dramatiza a semeadura de uma docência sem fronteiras. 


\section{Contracanto a palo seco, per via di levare}

Terminar aqui é iniciar uma tarefa em outro lugar, claro. O paradoxo aparente de um procedimento menos - nosso pequeno romance de bolso (Barthes, 2003a) - reside em sua voracidade crítico-exploratória, no modo como a palavra, tornada valor, emprega a faca e o cinzel no próprio corpo, subtraindo vícios, reorientando suas direções e seus sentidos, seus deslocamentos, quase princípios. O menos contra o mais, eis o gesto que sustentamos - e que, uma vez mais pela esteira barthesiana, denominamos poético:

Pode-se chamar de "poético" (sem julgamento de valor) todo discurso no qual a palavra conduz a ideia: se você ama as palavras a ponto de sucumbir a elas, você se retira da lei do significado, da escrevência. É, ao pé da letra, um discurso onírico (nosso sonho agarra as palavras que passam sob seu nariz e faz delas uma história). Meu próprio corpo (e não somente minhas ideias) pode ajustar-se às palavras, ser, de certo modo, criado por elas (Barthes, 2003a, p.169).

É através dessa palavra carnal que buscamos traçar um entre-lugar de ação em meio à estética da vigilância que caracteriza a "biopolítica porosa" (Beiguelman, 2021, p. 72) da dadosfera contemporânea, marcada pelo controle molecular dos corpos desde seu interior, distribuindo-os no fluxo dos territórios informacionais. Em um cenário de naturalização de armas travestidas de termômetros e de onipresença de câmeras cuja função principal é recolher a assinatura espectral de nossos corpos, não é de se admirar que dispositivos de regulação da docência a partir de observação, mensuração e controle de ações, recebam uma nova concessão para existir.

Há, então, uma disposição em lutar as lutas que nos tocam em uma zona poética que configura os sonhos, os frutos e as manhãs no entre-lugar da docência: ao pé da palavra, céu acima. Docência e pesquisa que se recusam, portanto, a escrever e a participar da reiteração da lei e da imposição do significado via os roteiros preferenciais dos currículos normativos e dos dispositivos duplamente mortíferos da atualidade.

Não silenciaremos e não obrigaremos a dizer.

O contracanto está no grão da voz, nó de palavras de uma razão antropofágica que agarra de modo crítico e assimila os discursos que circundam e são introjetados em nosso corpo. Com tal voragem, retomamos os esforços já realizados e testemunhamos a pesquisa e a docência como escolha ativa de uma tradição de ruptura, uma filiação que desliza, por intermédio da invenção de um repertório que é o sumo diferencial de nós mesmos, herança cultural já devorada.

Daí que a palavra carnal, corpórea, é, no limite, análoga a esses objetos aparentemente sem valor que as crianças adotam para si e carregam para todos os lados. Como para a criança, tais palavras-valor (eleitas porque desejáveis) funcionam como objetos transicionais (Winnicott, 2019), e por isso não deixam de ter um estatuto incerto: ao instaurar um espaço de jogo - dentro do qual o corpo obedece a uma física de atração e repulsa diante de outros corpos - a "palavra transicional" (Barthes, 2003a, p. 146) coloca em cena uma ausência do 
sentido (assim como o objeto transicional representa a ausência do adulto cuidador). Apesar da dureza de seus contornos, a despeito de suas repetições e de seu consequente desgaste pelo uso, essa palavra que é trabalhada no vai-e-vem da fala e da escuta e da escrita e da leitura, funciona como uma força fluida, que flutua como um desejo ardente.

Em nosso trabalho, estamos a apanhar bólides no ar.

Ao pé da palavra, a operação de uma docência-menos: palavra-carne, na qual se lê o estremecimento de um fazer futuro - algo como um apetite, sopra-nos Barthes (2003a) aos ouvidos, pela última vez. Porque o menos é também demanda da escuta como postura de aprontamento poético, disposição corpórea para um canto ex-cêntrico de apropriação e transcriação - "monadologia da palavra-canibal" que "começa no momento em que eu paro / mas já não sou mais capaz de dizê-lo" (Corazza, 2008, p. 22). Há sempre algo de imprevisível, o prazer próprio de um por fazer, na inscrição de um entre-lugar: aqui, ali, por entre imagens e sons unificados pela sucumbência à palavra-guia, zona de transição entre guitarras e cantos, campo e mar, céu acima, ensinar e aprender.

\section{Notas:}

1. Ao largo, diríamos que a noção de discurso da qual nos valemos parte de Michel Foucault em Arqueologia do saber (2008). Amiúde, contudo, filiamo-nos a Roland Barthes, tentando desenvolver "um discurso que não se enuncie em nome da Lei e/ou da Violência: cuja instância não seja nem política, nem religiosa, nem científica; que seja, de certa forma, o resto e o suplemento de todos esses enunciados. Como chamaríamos esse discurso? erótico, sem dúvida, pois ele tem a ver com o gozo; ou talvez ainda: estético, se previrmos submeter pouco a pouco essa velha categoria a uma ligeira torção, que a afastará de fundo regressivo, idealista, e a aproximará do corpo, da deriva" (2003a, p.97).

2. Nessa mesma aula, encontramos a seguinte afirmação: "[...] o que pode ser opressivo num ensino não é finalmente o saber ou a cultura que ele veicula, são as formas discursivas através das quais ele é proposto" (Barthes, 2007, p. 41). Se o ensino barthesiano nos interessa, é justamente por sua moralidade da forma, isto é, pela ética centrada no uso da linguagem na qual se fundamenta e se efetiva a ação humana - moralidade que é desdobrada, em aula, pelo jogo com o sentido, pela relação desarmada com as palavras, por táticas de recuo a partir das quais um algo a mais, não previsto, pode ter lugar. Falando sobre sua experiência nos seminários, Leyla Perrone-Moisés (2012, p. 126) faz referência ao modo como Barthes praticava a escuta, dando protagonismo à narrativa articulada pelos gestos. Nesse texto corporal, "os alunos se educavam menos pelas respostas do mestre do que pelo modo como ele ouvia".

\section{Referências}

ANDRADE, Oswald. Manifesto Antropófogo e outros textos. São Paulo: Penguin Classics Companhia das Letras, 2017.

AQUINO, Julio Groppa. Da autoridade pedagógica à amizade intelectual: uma plataforma para o éthos docente. São Paulo: Cortez, 2014.

AQUINO, Julio Groppa. Educação pelo arquivo: ensinar, pesquisar, escrever com Foucault. São Paulo: Intermeios, 2019. 
ARENDT, Hannah. Entre o passado e o futuro. São Paulo: Perspectiva. 1979.

BHABHA, Homi. O Local da Cultura. Belo Horizonte: Editora UFMG, 2001. 24

BARTHES, Roland. A câmara clara: nota sobre a fotografia. Rio de Janeiro: Nova Fronteira, 1984.

BARTHES, Roland. Roland Barthes por Roland Barthes. São Paulo: Estação Liberdade, 2003a.

BARTHES, Roland. Como viver junto: simulações romanescas de alguns espaços cotidianos. São Paulo: Martins Fontes, 2003b.

BARTHES, Roland. O rumor da língua. São Paulo: Martins Fontes, 2004.

BARTHES, Roland. A preparação do romance II: a obra como vontade. São Paulo: Martins Fontes, 2005.

BARTHES, Roland. Aula: aula inaugural da cadeira de semiologia literária do Colégio de França, pronunciada em 7 de janeiro de 1977. São Paulo: Cultrix, 2007.

BEIGUELMAN, Giselle. Políticas da imagem: Vigilância e resistência na dadosfera. São Paulo: Ubu Editora, 2021.

BOURRIAUD, Nicolas. Pós-produção: como a arte reprograma o mundo contemporâneo. Tradução Denise Bottmann. São Paulo: Martins, 2009.

BUTLER, Judith. Traços humanos nas superfícies do mundo. 2020. Disponível em: https://n1edicoes.org/042. Acesso em 25 mai. 2020.

CAMPOS, Haroldo de. Metalinguagem \& outras metas: ensaios de teoria e crítica literária. São Paulo: Perspectiva, 2017.

CAMPOS, Augusto de; PIGNATARI, Décio; CAMPOS, Haroldo de. Teoria da poesia concreta: textos críticos e manifestos 1950-1960. Cotia: Ateliê Editorial, 2006.

CORAZZA, Sandra Mara. Manifesto (della scrilettura cannibale). In: CORAZZA, S. M. Os cantos de Fourour: escrileitura em filosofia-educação. Porto Alegre: Sulina, Editora da UFRGS, 2008, p.21-47;

CORAZZA, Sandra Mara. O que se transcria em educação? Porto Alegre: UFRGS; Doisa, 2013.

CORAZZA, Sandra Mara. Uma introdução aos sete conceitos fundamentais da docência-pesquisa tradutória: arquivo EIS AICE. Pro-Posições, Campinas, SP, v. 29, n. 3, p. 92-116, 2018. Disponível em: https://periodicos.sbu.unicamp.br/ojs/index.php/proposic/article/view/8656398. Acesso em 29 ago. 2021.

DUNKER, Christian. Paixão da ignorância: a escuta entre Psicanálise e Educação. São Paulo: Editora Contracorrente, 2020.

FAUSTO, Juliana. Contra quem se vingam os animais? 2020. Disponível em: https://n-1edicoes.org/040. Acesso em 23 mai. 2020.

FOUCAULT, Michel. A arqueologia do saber. Rio de Janeiro: Forense Universitária, 2008.

FREUD, Sigmund. Fundamentos da clínica psicanalítica. Belo Horizonte: Autêntica Editora, 2017.

HAN, Byung-Chul. Topologia da violência. Petrópolis: Vozes, 2017.

HAN, Byung-Chul. Psicopolítica - O neoliberalismo e as novas técnicas de poder. Belo Horizonte: Editora Âyiné, 2018.

HARAWAY, Donna J. Ficar com o problema. 2020. Disponível em: https://n-1edicoes.org/137. Acesso em 08 ago. 2020.

HOOKS, bell. Ensinando a transgredir: a educação como prática da liberdade. São Paulo: Editora WMF Martins Fontes, 2017.

LISPECTOR, Clarice. Água viva. São Paulo: Rocco, 1998.

LOLLO, Paolo. Psicanálise e transmissão do saber. Trivium, Rio de Janeiro, v. 5, n. 1, p. 15-20, jun. 2013. Disponível em <http://pepsic.bvsalud.org/scielo.php?script=sci_arttext\&pid=S2176- 
$48912013000100003 \& \operatorname{lng}=$ pt\&nrm=iso>. Acesso em 28 ago. 2021.

MASSCHELEIN, Jan. Fazer escola: a voz e a vida do professor. In: Elogio do professor. LARROSA, Jorge; RECHIA, Karen Christine; CUBAS, Caroline Jaques (Orgs.). Belo Horizonte: Autêntica Editora, 2021, p.25-46.

MBEMBE, Achille. O direito universal à respiração. 2020. Disponível em: https://n-1edicoes.org/020. Acesso em 25 mai. 2020.

MEZAN, Renato. A sombra de Don Juan e outros ensaios. São Paulo: Casa do Psicólogo, 2005.

MIZOGUCHI, Danichi H.; PASSOS, Eduardo. Epidemiologia política. 2020. Disponível em: https://n1edicoes.org/015. Acesso em 18 mai. 2020.

MUNHOZ, Angélica Vier.; COSTA, Cristiano Bedin da; LULKIN, Sergio Andrés. (Orgs.). Porque esperamos [notas sobre a docência, a obsolescência e o vírus]. Porto Alegre: UFRGS, 2020. Disponível em: https://lume.ufrgs.br/handle/10183/210654. Acesso em 30 jun. 2020.

NAFFAH-NETO, Alfredo. Outr'em mim. São Paulo: Plexus Editora, 1998.

NETO, João Cabral de Melo. A educação pela pedra. São Paulo: Alfaguara, 2008.

PAZ, Octavio. La tradición de la ruptura. In: PAZ, O. La casa de la presencia - Poesía e Historia. México: Fondo de Cultura, s/d, p. 129-134.

PERRONE-MOISÉS, Leyla. Com Roland Barthes. São Paulo: Editora WMF Martins Fontes, 2012.

PRECIADO, Paul B. Aprendendo do vírus. 2020. Disponível em: https://n-1edicoes.org/007. Acesso em 27 abr. 2020.

SANTIAGO, Silviano. Uma literatura nos trópicos. Recife: Cepe, 2019.

WINNICOTT, Donald W. O brincar e a realidade. São Paulo: Ubu Editora, 2019.

\section{Correspondência}

Cristiano Bedin da Costa: Psicólogo; Docente da Faculdade de Educação e do Programa de Pós-Graduação em Educação da Universidade Federal do Rio Grande do Sul (UFRGS); Coordenador da Rede de Pesquisa Escrileituras da Diferença em Filosofia-Educação; Atua em uma Zona de Investigações Poéticas (ZIP).

E-mail: cristianobedindacosta@ gmail.com

Marcos da Rocha Oliveira: Pedagogo, Mestre e Doutor em Educação pela Universidade Federal do Rio Grande do Sul (UFRGS); Professor na Universidade Federal do Paraná (UFPR); Atua em uma Zona de Investigações Poéticas (ZIP).

E-mail: marqosoliveira@gmail.com

Texto publicado em Currículo sem Fronteiras com autorização dos autores. 